\title{
Delayed entry into HIV care after diagnosis in two specialized care and treatment centres in Cameroon: the influence of CD4 count and WHO staging
}

Noah F. Takah ${ }^{1,2,4^{*}}$, George Awungafac ${ }^{1,2}$, Leopold N. Aminde ${ }^{2,3,4}$, Innocent Ali ${ }^{1,5}$, Juliana Ndasi ${ }^{1}$ and Patrick Njukeng ${ }^{1,5}$

\begin{abstract}
Background: Delayed entry into HIV care has complicated the challenges faced in sub-Saharan Africa due to the high HIV burden. A clear knowledge of the factors affecting delayed entry will be essential in directing interventions towards reducing delayed entry into HIV care. There exist very limited data on delayed entry in Cameroon despite its relevance; hence this study was conducted to determine the rate of delayed entry and its associated factors in HIV programmes in Cameroon.

Methods: Data used for this study was routine data obtained from the files of HIV patients who were diagnosed between January 1, 2015 and June 30, 2015 at Limbe and Buea regional hospital HIV centers in the South West region of Cameroon. Data analysis was done using SPSS version 20.

Results: Of the 223 patients included in the study, nearly one-quarter of patients (22.4\%) delayed to enter HIV care within 3 months. Those who delayed to enter care were less likely to present at first diagnosis (using HIV rapid test) with symptoms such as fever $>1$ month ( $5 \%$ versus $30 \%, p=0.01$ ) and weight loss $>10 \%$ (13\% versus $48 \%, p<$ 0.001). Alcohol consumption, WHO stage and CD4 count levels were also associated with delayed entry in bivariate analysis. In multivariate analysis only CD4 count greater than 500cells/ $\mu$ land WHO stages I and II were independently associated with delayed entry into HIV care within 3 months.

Conclusion: In the South West region of Cameroon, approximately 1 out of 4 patients delay to enter HIV care. This high proportion of patients who delay to enter care correlates to the findings recorded by other studies in sub Saharan Africa. Interventions tackling delayed entry into HIV care might need to be favorably directed towards patients that have high CD4 counts and are at very early WHO clinical stages.
\end{abstract}

Keywords: Delayed entry, Factors associated

\section{Background}

The global burden of HIV is clearly unevenly distributed with sub-Saharan Africa having the greatest share of the spread and sequelae of the pandemic [1,2]. With an estimated 24.7 million people living with HIV in subSaharan Africa, accounting for almost $71 \%$ of the global HIV burden, the region continues to face enormous

\footnotetext{
* Correspondence: takahnoah@yahoo.com

${ }^{1}$ Global Health Systems Solutions, Limbe, Cameroon

${ }^{2}$ Faculty of Health Sciences, University of Buea, Buea, Cameroon

Full list of author information is available at the end of the article
}

challenges to control the spread of the pandemic as well as to adequately and effectively managed old and newly infected people living with HIV [3]. Despite the successes registered so far in the domain of increasing access to antiretroviral medications and curbing the spread of new HIV infections, the effective tracking and monitoring of HIV infected patients still present as daunting challenges that urgently need to be addressed for the success of HIV care programmes in the sub-Saharan Africa region [4-10]. 
All across Africa (sub-Saharan Africa and Cameroon in particular),the United States (US) President's Emergency Plan For AIDS Relief (PEPFAR) through the US Centres for Disease Control and Prevention (CDC) have directed substantial amounts of funds towards addressing the challenges faced by countries towards HIV diagnosis [11]. Through local implementing partners, the efforts of PEPFAR and the CDC have resulted in improved CD4 testing that ensures the issuing of same day CD4 test results to newly diagnosed HIV positive patients [12, 13]. Despite these efforts, several studies in Africa have reported delayed entry into HIV care and loss to follow up after initial HIV diagnosis [14-16]. Delayed entry into HIV care has been defined by the World Health Organization [17] and from several published studies as not having a CD4 measurement within 3 months of HIV diagnosis [18-20]. A better understanding of the factors affecting delayed entry before antiretroviral therapy initiation will be necessary in guiding interventions towards ensuring timely CD4 measurement and eventual enrolment into the HIV continuum of care [21]. Despite the relevance of studies in delayed entry into HIV care, there exist limited published data on its epidemiology in Cameroon. This study was therefore designed and conducted to determine the prevalence of delayed entry into HIV care, the socio-demographic and clinical profiles of patients newly diagnosed of HIV and the factors that are associated with delayed entry into HIV care in Cameroon.

\section{Methods}

\section{Study design and Area}

This was a cross-sectional study conducted in the two major HIV care and treatment centres in the South West region of Cameroon namely the Buea Regional and Limbe Regional Hospitals, from the 1st January 2015 to June 30th 2015. The hospitals selected cover more than two thirds of the total HIV population in the South West region and are well situated in the Regional Capital (Buea health district with population $=133,092$ inhabitants) and the Divisional Capital (Limbe health district with population $=151,258$ inhabitants) with relatively high population densities. Both centres are equipped with the Alere PIMA CD4 point of care diagnostic machines permitting the issuing of same day CD4 results. Each of the centres receives averagely 2023 newly diagnosed HIV positive patients every month.

\section{Sample size and sampling technique}

A convenience sampling technique was used. A total of 223 adult ( $\geq 18$ years) non pregnant patients who presented at both centres and were newly diagnosed HIV positive between January 1st 2015 to June 30th 2015 were included in the study consecutively.

\section{Data collection and study procedure}

Data used for this study was routine data obtained from the files of HIV patients who were diagnosed between January 1, 2015 and June 30, 2015 at Limbe and Buea regional hospitals HIV centers in the South West region of Cameroon. A structured data collection form was developed by the research team following the flow of HIV programme activities from patient identification, consultation, pre-test counselling and testing and posttest counselling in the two centres. The data collection form consisted of socio-demographic characteristics, the medical history of the patients, the clinical presentation and WHO staging, the laboratory tests and the date when HIV rapid test and CD4 test were done. The socio-demographic characteristics included the age, sex, religion (Christian, Muslim and others), marital status, educational level, household size, sharing of results, occupation, place of residence and time taken to reach treatment centres. The educational level was classified based on the level of study and/or certificates obtained. The educational levels were classified into primary (if elementary school was attended and/or first school living certificate was obtained), secondary (if college was attended and/or college certificates obtained) and university education (if a school of higher learning was attended and/or certificates obtained). The number of family members in each household (household size) was recorded. The time taken to reach the treatment centres was classified into less than $1 \mathrm{~h}$ and greater than $1 \mathrm{~h}$. The data collection form also included questions on whether the participants shared their results with close family members (wife, children, siblings or parents) or friends by showing the HIV test result to them. In the medical history, presence of other associated chronic diseases (Tuberculosis, diabetes, hypertension and hepatitis) and sexually transmitted infections was noted. Alcohol consumers were classified into low, moderate and excessive alcohol consumers. Excessive alcohol consumption was based on intake of either more than 3 (2 for women) standard glasses of wine per day or more than 10 (5 for women) local beers (1 local beer contains $28 \mathrm{~g}$ of alcohol) per week. Moderate alcohol consumption was based on intake of 25-30 g per day. The clinical symptoms and signs were noted for each patient by the nurses at the treatment centre and this was used to classify the patients according to the World Health Organization (WHO) staging [22]. The laboratory tests performed by the patients were also collected and included HIV rapid tests (for HIV $1 / 2$ and the time when test was performed), CD4 test (the value and the time test was performed), hemoglobin and full blood count. The drug history of the patients was also noted.

After the administrative and ethical approvals had been obtained, the investigators proceeded to complete 
the data collection form, using the information from the files of the patients that were initially filled by the nurses at the care and treatment centres.

\section{Definition of delayed entry}

A patient was said to have delayed to enter HIV care if he/ she did not have a CD4 measurement within 3 months of HIV diagnosis $[18,23]$.

\section{Data analysis}

Data were analyzed using the Statistical Package for Social Sciences (SSPS Inc, Chicago, Illinois, USA) version 20.0 software. Results are summarized as counts and percentages for categorical variables and as mean and standard deviation (SD) for quantitative variables. Group comparison used the Student $t$-test for quantitative variables and the chi-square test for categorical variables. To assess the factors associated with delayed entry, bivariate and multivariate logistic regression models were used. A $p$-value 0.05 was considered statistically significant.

We controlled for confounding in the analysis by using a multiple logistics regression through backward elimination in which if a variable was suspected to be confounder, we removed the variable from the model and checked if the odds ratios and significance of the rest of the variables left in the new model changed significantly. If removing a variable from the model resulted in a significant change in the odds ratios, they were maintained in the model even if they were statistically insignificant.

\section{Results}

\section{Clinical characteristics of the study population}

In this study, the participants were between 18 and 65 years old with a median age of 32 years. 88 (39.5\%) of the participants were between 21 and 30 years old, 140 (62.8\%) of the participants were females and 90 (43.7\%) had primary education (Table 1). In addition, 178 (79.8\%) shared their results with close family members (Table 2 ).

\section{Prevalence of delayed entry into HIV care and its associated factors}

Our findings reveal that, nearly 1 out of 4 patients (22.4\%) delayed to enter care within 3 months of initial HIV diagnosis (Table 2). Those who delayed to enter care were less likely to present for HIV rapid testing with symptoms such as fever $>1$ month (5\% versus $30 \%, p=0.01)$ and weight loss $>10 \%$ (13\% versus $48 \%$, $p<0.001$ ) (Table 2). Alcohol consumption, WHO stage and CD4 count levels were also associated with delayed entry in bivariate analysis (Table 2 and Table 3). The presence of symptoms such as fever and weight loss seemed to be strong predictors of delayed entry (and indirectly care seeking behaviour) but further analysis
Table 1 Socio-demographic characteristics of the study population $(N=223)$

\begin{tabular}{|c|c|c|}
\hline Characteristics & Frequency/Mean \pm SD & Percentage \\
\hline $\begin{array}{l}\text { Age, Mean } \pm \quad \text { SD, } \\
\text { median(range) }\end{array}$ & $33.3 \pm 9.3,32(18-65)$ & \\
\hline \multicolumn{3}{|l|}{ Age groups } \\
\hline$<20$ & 11 & 4.9 \\
\hline $21-30$ & 88 & 39.5 \\
\hline $31-40$ & 74 & 33.2 \\
\hline $41-50$ & 39 & 17.5 \\
\hline $51-60$ & 10 & 4.5 \\
\hline$>60$ & 01 & 0.4 \\
\hline \multicolumn{3}{|l|}{ Gender } \\
\hline Male & 83 & 37.2 \\
\hline Female & 140 & 62.8 \\
\hline \multicolumn{3}{|l|}{ Religion } \\
\hline Christian & 198 & 88.8 \\
\hline Muslim & 25 & 11.2 \\
\hline \multicolumn{3}{|l|}{ Marital status } \\
\hline Married & 81 & 36.3 \\
\hline Single & 128 & 57.4 \\
\hline Widow(er) & 14 & 6.3 \\
\hline \multicolumn{3}{|l|}{ Educational level } \\
\hline Never & 19 & 9.2 \\
\hline Primary & 90 & 43.7 \\
\hline Secondary & 73 & 35.4 \\
\hline Higher/University & 24 & 11.7 \\
\hline
\end{tabular}

revealed that they were confounded by the WHO stages I and II. In multivariate analysis, only CD4 count greater than 500cells/ $\mu \mathrm{l} 3.6(0.6-10.4, p=0.012]$ and WHO stages I and II $5.4(1.9-15.2, p=0.01]$ were independently associated with delayed entry into HIV care within 3 months (Table 3).

In the backward elimination method of adjustment for confounders in the regression model, removal of the variables such as age, gender and alcohol consumption led to significant changes in the odds ratios of CD4 and WHO stage. These variables were therefore maintained in the model.

\section{Discussion}

Our study reveal that the proportion of those who delayed to enter HIV care was nearly 1 out of 4 patients. This high proportion of delayed entry was driven by high CD4 count at first diagnosis and early WHO clinical stages (stages I and II).

The high percentage of those who delay to enter HIV care observed in our study is comparable to many other studies that have been carried out in other parts of the 
Table $\mathbf{2}$ Characteristics of the study population according to delay entry status

\begin{tabular}{|c|c|c|c|c|}
\hline Characteristics & Total $(N=223) n(\%)$ or mean \pm SD & Delayed $(N=50) n(\%)$ or mean $\pm S D$ & Not delayed $(N=173) n(\%)$ or mean \pm SD & $p$-value \\
\hline Age & $33.3 \pm 9.3$ & $33.4 \pm 11.3$ & $33.3 \pm 8.7$ & 0.10 \\
\hline \multicolumn{5}{|l|}{ Gender } \\
\hline Male & $83(37.2)$ & $19(38.0)$ & $64(36.9)$ & \multirow[t]{2}{*}{0.10} \\
\hline Female & $140(62.8)$ & $31(62.0)$ & $109(63.1)$ & \\
\hline Result shared & 178(79.8) & $30(60.0)$ & $148(85.5)$ & 0.92 \\
\hline Alcohol & $121(54.3)$ & $34(68.0)$ & $87(50.3)$ & 0.04 \\
\hline \multicolumn{5}{|l|}{ WHO HIV stage } \\
\hline WHO I & $125(56.1)$ & $20(40.0)$ & $105(61.0)$ & \multirow[t]{4}{*}{$<0.001$} \\
\hline WHO ॥ & $38(17.0)$ & $17(34.0)$ & $21(12.0)$ & \\
\hline WHO III & $54(25.2)$ & $10(20.0)$ & $44(25.0)$ & \\
\hline WHO IV & $06(2)$ & $3(6.0)$ & $04(2.0)$ & \\
\hline Fever $>1$ month & $35(15.7)$ & $5(10.0)$ & $30(17.3)$ & 0.010 \\
\hline Weight loss > $10 \%$ & $47(21.1)$ & $23(13.3)$ & $24(48.0)$ & $<0.001$ \\
\hline CD4 count & $441.4 \pm 279.3$ & $458.2 \pm 281.7$ & $384.7 \pm 266.2$ & 0.01 \\
\hline Travel hours to TC & $0.7 \pm 1.4$ & $0.7 \pm 1.5$ & $0.3 \pm 0.6$ & 0.082 \\
\hline
\end{tabular}

World such as the United States and Europe. Rosen and colleagues carried out a systematic review between testing and treatment initiation in sub Saharan Africa and demonstrated that the rate of delay entry between HIV diagnosis and receipt of first CD4 measurement varies between $12 \%$ and $65 \%$ [24]. The proportion of those who delay to enter HIV care in our study is also quite close to the $29.7 \%$ reported by Alvarez-Uria and colleagues [25] in India and $23.2 \%$ reported by Jennes and associates [20] in the United States. Delayed entry into care therefore cuts across both developed and developing settings of the World with its highest rate in sub Saharan Africa. This similar rates of delayed entry with non-African settings can be due to the similarity in the patterns of factors associated with delay entry such as refusal to accept HIV status in both African and nonAfrican settings [20]. The high percentage of those who delay to enter HIV care in our setting can be linked to the fact that in the early era of rapid antiretroviral treatment (ART) scale up, much attention was directed towards initiating eligible patients on ART while those who were HIV positive and not eligible (that is those in the pre-HAART period) were not given enough attention and follow up [24]. Furthermore, the rate of delayed entry can be even higher if a single group of patients is put under investigation [26].

Several studies in Africa have attempted to investigate the factors associated with the phenomenon of delayed entry into HIV care [14, 21, 25, 27]. In our study, we investigated if factors such age, gender, educational level, alcohol consumption, travel hours from the treatment centres, sharing of results with a family member or friend,anemia,CD4 count on first diagnosis and WHO clinical staging were associated with delayed entry. From our study, high CD4 (greater than 500cells/ $\mu$ l) and WHO stages I and II were strongly associated with delay entry. While many studies have reported this positive relationship between high CD4 and delayed entry $[15,18,25,28]$ some other studies in GuineaBissau and Uganda have reported an association between low CD4 count and delayed entry $[9,29]$. The relationship between high CD4 count and delay entry may be related to the observation that most of such patients feel healthy or asymptomatic (WHO stage I) $[18,29]$, and they may tend to think they still have some time before development of symptoms or they may live in denial, refusing to accept their HIV status. Even though our study showed that age was not significantly associated with delayed entry, there exist some evidence from other studies that young age is significantly associated with other factors which may be related to delayed entry into care such as acceptance of HIV positive status and initiation on lifelong antiretroviral therapy tend to be problematic among young HIV patients [30, 31].

Using a convenient sample and a cross sectional study design poses some limitations. Importantly, a cross sectional study design can only describe temporal relationships between factors observed and the outcome irrespective of the strength of the associations observed, and therefore only provides plausible hypotheses that can be explored using other study designs [32]. Variables such as sharing of results may change over time as participants receive appropriate post-test counselling. This could not be captured by a cross sectional study design. Using a consecutive sample in a hospital setting means 
Table 3 Factors associated with delay entry into HIV care within 3 months; Logistics regression analysis

\begin{tabular}{|c|c|c|c|c|}
\hline \multirow[t]{2}{*}{ Characteristics } & \multicolumn{2}{|l|}{ Bivariate analysis } & \multicolumn{2}{|c|}{ Multivariate analysis } \\
\hline & OR $(95 \% \mathrm{Cl})$ & $\overline{p \text {-value }}$ & OR $(95 \% \mathrm{Cl})$ & $p$-value \\
\hline \multicolumn{5}{|l|}{ Age } \\
\hline$>32$ years & Ref & & & \\
\hline$\leq 32$ years & $1.5(0.8-3.1)$ & 0.10 & $2.8(0.6-2.3)$ & 0.18 \\
\hline \multicolumn{5}{|l|}{ Gender } \\
\hline Female & Ref & & & \\
\hline Male & $3.5(1.3-9.2)$ & 0.10 & $1.2(0.8-5.5)$ & 0.22 \\
\hline \multicolumn{5}{|l|}{ Educational level } \\
\hline Higher & Ref & & & \\
\hline $\mathrm{Nil}$ & $2.1(0.3-13.8)$ & 0.45 & & \\
\hline Primary & $1.7(0.4-8.1)$ & 0.51 & & \\
\hline Secondary & $0.5(0.1-3.0)$ & 0.43 & & \\
\hline \multicolumn{5}{|l|}{ Alcohol } \\
\hline No & Ref & & & \\
\hline Yes & $2.7(1.9-7.9)$ & 0.04 & $1.5(0.5-4.8)$ & 0.47 \\
\hline \multicolumn{5}{|l|}{ Anaemia } \\
\hline $\mathrm{Hb} \leq 9 \mathrm{~g} / \mathrm{dL}$ & Ref & & & \\
\hline $\mathrm{Hb}>9 \mathrm{~g} / \mathrm{dL}$ & $2.6(0.2-30.2)$ & 0.43 & & \\
\hline \multicolumn{5}{|l|}{ CD4count } \\
\hline 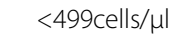 & Ref & & & \\
\hline$\geq 500 \mathrm{cells} / \mu \mathrm{l}$ & $4.9(1.4-17.5)$ & 0.01 & $3.6(0.6-10.4)$ & 0.012 \\
\hline \multicolumn{5}{|c|}{ Travel hours to TC } \\
\hline$\leq 1 \mathrm{~h}$ & Ref & & & \\
\hline$>1 \mathrm{~h}$ & $1.2(0.3-4.5)$ & 0.75 & & \\
\hline \multicolumn{5}{|l|}{ WHO-HIV stage } \\
\hline WHO III\&IV & Ref & & & \\
\hline WHO I \& II & $6.1(2.3-16.2)$ & $<0.001$ & $5.4(1.9-15.2)$ & 0.01 \\
\hline \multicolumn{5}{|l|}{ Sharing of result } \\
\hline No & Ref & & & \\
\hline Yes & $1.2(0.7-3.4)$ & 0.92 & & \\
\hline
\end{tabular}

our study is prone to selection bias and might not be representative of the population of HIV positive patients in Cameroon. This warrants further multicenter studies which also include individuals diagnosed in non-hospital settings such as community outreach. Using routine data captured in the files of patients led to some missing data on alcohol consumption. The quality of data collected on variables such as alcohol consumption would have been much better if face to face interviews were conducted. Due to this limitation in the quality of data collected on alcohol consumption, the association with delayed entry into HIV care should be interpreted with caution. However, in our setting where diagnosis of HIV is still associated with a substantial level of stigma, face to face interviews would have markedly resulted in a low response rate and small sample size for the study. In terms of the representativeness of our sample, since we included all HIV patients diagnosed within the period of study in the two main centres responsible for HIV care in the South West region of Cameroon, our sample could be representative of patients diagnosed within health care settings in this region of the country. With regards to data collection, despite the missing data on alcohol consumption, we encountered very little challenges on the quality of data collected on other variables because we ensured that the nurses that were in-charge of filling in and coding patient files were all trained on quality of data recording. Furthermore, it is necessary to also note that this study is the first of its kind in the subject of delayed entry in Cameroon and in an era of greater emphasis on testing, treating, tracking and follow up of HIV patients, its relevance cannot be overemphasized. Our findings provide some key information that would guide interventions to address delayed entry into HIV care after diagnosis by suggesting the group of newly diagnosed HIV patients to be suitably targeted in our setting; with the goal of reducing cascade losses at a key point in the HIV care continuum. Consequently, a larger multicenter cohort study is urgently needed to fine tune our observations made so far by establishing with a higher degree of certainty the predictors of delayed entry in our setting.

\section{Conclusion}

In the South West region of Cameroon, approximately 1 out of 4 patients delay to enter HIV care. This high proportion of patients who delay to enter care correlates to the findings recorded by other studies in sub Saharan Africa. Interventions tackling delay entry into HIV care might need to be favorably directed towards patients that have high CD4 counts and are at very early WHO clinical stages.

\section{Abbreviations}

CDC, centres for disease control and prevention; HIV, human

immunodeficiency virus; PEPFAR, president's emergency plan for AIDS relief; WHO, World Health Organization.

\section{Acknowledgements}

The authors would like to thank the South West Regional Delegation for Public Health for the authorizing the sites to participate. We also thank the nurses at these clinical sites for assisting in data collection.

\section{Funding}

None.

\section{Availability of data and materials}

The raw data supporting our findings have been stored in the various hospital ethical committee records and the secured database of the South West Regional Delegation for Public Health, Cameroon. We do not intend to share the raw data because even though the individual patient names and identify were coded, sensitive information about the centres were captured in the database which we regrettably find unacceptable to share with a third party for administrative and political reasons. 


\section{Authors' contribution}

Conceived and designed the study: NFT, GA, LNA, IMA, JN and PN. Data collection: NFT and GA. Data analysis: LNA, NFT and GA. Wrote of manuscript: NFT. Reviewed manuscript: NFT, GA, LNA, IMA, PN. All authors read and approved the final version of the manuscript before submission.

\section{Competing interest}

None declared.

\section{Consent to publish}

Not applicable.

\section{Ethics approval and consent to participate}

Ethical and administrative approvals were obtained from the South West Regional Delegation of the Ministry of Public Health $(\mathrm{MoPH})$ and authorities of Regional Hospitals. Authorization was obtained to access the files of patients that had been newly diagnosed of HIV. Consent was obtained from each patient by the nurses before initial enrolment into care. After obtaining authorization, the patient files were de-identified and study codes assigned for each patient by the nurses. No identifying information such as name, address, telephone number, date of birth or actual medical record number was recorded.

\section{Author details}

${ }^{1}$ Global Health Systems Solutions, Limbe, Cameroon. ${ }^{2}$ Faculty of Health Sciences, University of Buea, Buea, Cameroon. ${ }^{3}$ Sub divisional Hospital Nguti, Nguti, South West Region, Cameroon. ${ }^{4}$ Clinical Research Education, Networking and Consultancy, Douala, Cameroon. ${ }^{5}$ Virology Laboratory, University of Dschang, Dschang, Cameroon.

\section{Received: 8 August 2015 Accepted: 25 June 2016}

\section{Published online: 08 July 2016}

\section{References}

1. World Health Organization and UNAIDS 2015. Global AIDS Response Progress Report 2015. WHO Library Cataloguing-in-Publication data. ISBN 978-92-4-150934-3.

2. Ortblad KF, Lozano R, Murray CJL. The burden of HIV: insights from the Global Burden of Disease Study 2010. AIDS 2013;27:2003-2017.

3. UNAIDS. The Gap report. UNAIDS report on Global AIDS epidemic 2013. ISBN 978-92-9253-032-7

4. Fenner $\mathrm{L}$, Brinkhof MWG, Keiser $\mathrm{O}$, Weigel $\mathrm{R}$, Cornell $\mathrm{M}$, Moultrie $\mathrm{H}$, et al. Early mortality and loss to follow-up in HIV-infected children starting antiretroviral therapy in Southern Africa. J Acquir Immune Defic Syndr. 2010; 54:524-32.

5. Horstmann E, Brown J, Islam F, Buck J, Agins BD. Retaining HIV-infected patients in care: Where are we? Where do we go from here? Clin Infect Dis. 2010;50:752-61.

6. Losina $E$, Touré $H$, Uhler LM, Anglaret $X$, Paltiel AD, Balestre $E$, et al. Cost-effectiveness of preventing loss to follow-up in HIV treatment programs: A Côte d'Ivoire appraisal. PLoS Med. 2009;6(10):e1000173.

7. Losina E, Bassett IV, Giddy J, Chetty S, Regan S, Walensky RP, et al. The "ART" of linkage: Pre-treatment loss to care after HIV diagnosis at two PEPFAR sites in Durban, South Africa. PLoS One. 2010;5(3):e9538.

8. Bekolo CE, Webster J, Batenganya M, Sume GE, Kollo B. Trends in mortality and loss to follow-up in HIV care at the Nkongsamba Regional hospital, Cameroon. BMC Res Notes. 2013;6:512.

9. Amuron B, Namara G, Birungi J, Nabiryo C, Levin J, Grosskurth H, et al. Mortality and loss-to-follow-up during the pre-treatment period in an antiretroviral therapy programme under normal health conditions Uganda. BMC Public Health. 2009;9:290.

10. Togun T, Peterson I, Jaffar S, Oko F, Okomo U, Peterson K, et al. Pre-treatment mortality and loss-to-follow-up in HIV-1, HIV-2 and HIV-1/HIV-2 dually infected patients eligible for antiretroviral therapy in The Gambia, West Africa. AIDS Res Ther. 2011;8(1):24.

11. Stevens W, Gous N, Ford N, Scott LE. Feasibility of HIV point-of-care tests for resource-limited settings: challenges and solutions. BMC Med. 2014;12(1):1

12. Faal M, Naidoo N, Glencross DK, Venter WDF, Osih R. Providing immediate CD4 count results at HIV testing improves ART initiation. J Acquir Immune Defic Syndr. 2011;58:e54-9.
13. Patten GEM, Wilkinson L, Conradie K, Isaakidis $P$, Harries AD, Edginton ME, et al. Impact on ART initiation of point-of-care CD4 testing at HIV diagnosis among HIV-positive youth in Khayelitsha, South Africa. J Int AIDS Soc. 2013; 16:1-6.

14. Hassan AS, Fielding KL, Thuo NM, Nabwera HM, Sanders EJ, Berkley JA. Early loss to follow-up of recently diagnosed HIV-infected adults from routine pre-ART care in a rural district hospital in Kenya: a cohort study. Trop Med Int Health. 2012;17:82-93.

15. Geng EH, Nash D, Kambugu A, Zhang Y, Braitstein P, Christopoulos KA, et al. Retention in Care Among HIV-Infected Patients in Resource-Limited Settings: Emerging Insights and New Directions. Curr HIV/AIDS Rep. 2010;7:234-44.

16. Myer L, Zulliger R, Bekker L-G, Abrams E. Systemic delays in the initiation of antiretroviral therapy during pregnancy do not improve outcomes of HIVpositive mothers: a cohort study. BMC Pregnancy Childbirth. 2012;12:94.

17. World Health Organization. Retention in HIV programmes: defining the challenges and identifying solutions: meeting report, 13-15 September 2011. Available from http://www.who.int/iris/handle/10665/44878.

18. Alvarez-Uria G, Pakam R, Midde M, Naik PK. Predictors of delayed antiretroviral therapy initiation, mortality, and loss to followup in hiv infected patients eligible for hiv treatment: Data from an HIV cohort study in India. BioMed Res Int. 2013; 2013:849042.

19. Robertson M, Wei SC, Beer L, Adedinsewo D, Stockwell S, Dombrowski JC, et al. Delayed entry into HIV medical care in a nationally representative sample of HIV-infected adults receiving medical care in the USA. AIDS Care. 2016;28(3):325-33.

20. Jenness SM, Myers JE, Neaigus A, Lulek J, Navejas M, Raj-Singh S. Delayed entry into HIV medical care after HIV diagnosis: risk factors and research methods. AIDS Care. 2012;24(10):1240-8.

21. Dennis AM, Napravnik S, Sena AC, Eron JJ. Late entry to HIV care among latinos compared with non-latinos in a southeastern US cohort. Clin Infect Dis. 2011;53(5):480-7.

22. Teck R, Ascurra O, Gomani P, Manzi M, Pasulani O, Kusamale J, Salaniponi FM, Humblet P, Nunn P, Scano F, Harries AD. WHO clinical staging of HIV infection and disease, tuberculosis and eligibility for antiretroviral treatment: relationship to CD4 lymphocyte counts. Int J Tuber Lung Dis. 2005;9(3):258-62.

23. Fox MP, Larson B, Rosen S. Defining retention and attrition in pre-antiretroviral HIV care: Proposals based on experience in Africa. Trop Med Int Health. 2012; 17(10):1235-44.

24. Rosen S, Fox MP. Retention in HIV care between testing and treatment in sub-Saharan Africa: A systematic review. PLoS Med. 2011;8(7):e1001056.

25. Alvarez-Uria G. Factors associated with delayed entry into HIV medical care after HIV diagnosis in a resource-limited setting: Data from a cohort study in India. PeerJ. 2013;1:e90.

26. Ickovics JR, Forsyth B, Ethier KA, Harris P, Rodin J. Delayed entry into health care for women with HIV disease. AIDS Patient Care STDS. 1996;10:21-4.

27. Geng EH, Bwana MB, Muyindike W, Glidden DV, Bangsberg DR, Neilands TB, et al. Failure to initiate antiretroviral therapy, loss to follow-up and mortality among HIV-infected patients during the pre-ART period in Uganda. J Acquir Immune Def Syndr. 2013;63:e64-71.

28. Ahmed I, Gugsa ST, Lemma S, DAhmed I, Gugsa ST, Lemma S, et al. Predictors of loss to follow-up before HIV treatment initiation in Northwest Ethiopia: a case control study. BMC Public Health. 2013;13:867.

29. Hønge BL, Jespersen S, Nordentoft PB, Medina C, da Silva D, da Silva ZJ, et al. Loss to follow-up occurs at all stages in the diagnostic and follow-up period among HIV-infected patients in Guinea-Bissau: a 7-year retrospective cohort study. BMJ Open. 2013;3:e003499.

30. Kumwenda M, Tom S, Chan AK, Mwinjiwa E, Sodhi S, Joshua M, et al. Reasons for accepting or refusing HIV services among tuberculosis patients at a TB-HIV integration clinic in Malawi. Int J Tuberc Lung Dis. 2011;15:1663-9.

31. Naswa S, Marfatia YS. Adolescent HIV/AIDS: Issues and challenges. Indian J Sex Transm Dis. 2010:31(1):1-10.

32. Levin KA. Study design III: Cross-sectional studies. Evid Based Dent. 2006; 7(1):24-5. 